Conf-910lelez--9

SSCL-492

密

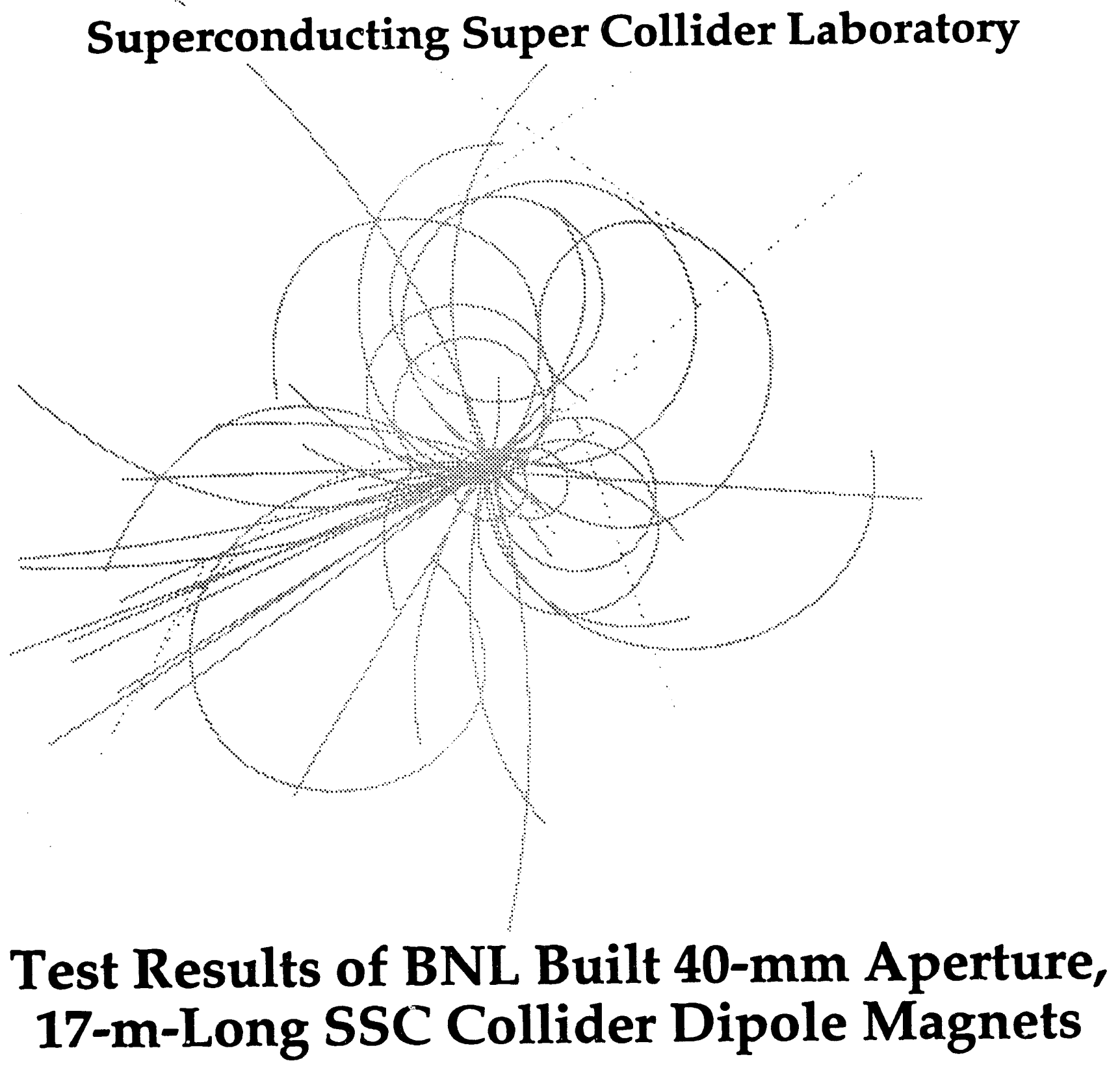

J. Kuzminski, T. Bush, A. Devred, et al.

June 1991

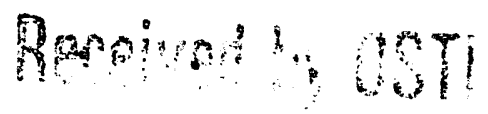




\title{
Test Results of BNL Built 40-mm Aperture, 17-m-Long SSC Collider Dipole Magnets*
}

\author{
J. Kuzminski, T. Bush, A. Devred, et al \\ Magnet Division \\ Superconducting Super Collider Laboratory ${ }^{\dagger}$ \\ 2550 Beckleymeade Ave. \\ Dallas, TX 75237
}

June 1991

\section{DISCLAIMER}

\begin{abstract}
This report was prepared as an account of work sponsored by an agency of the United States prepared as an account of work sponsored by an agency of thereof, nor any of their Government. Neither the United States Government nor any agency thereol, hor any of the employees, makes any warranty, express or implied, or assumes any legal habatitus, product, or bility for the accuracy, completeness, or usefulness of any informativately owned rights. Referprocess disclesed, or represents that its use would not infringe privately ow name, trademark, ence herein 10 any specific commercial product, process, or service by trade name, tradent, recommanufacturer, or otherwise does not necessarily constitute or imply its endorseref. The views mendation, or favoring by the United States Government or any agency therect those of the and opinions of authors expressed herein do not

United States Government or any agency thereof.
\end{abstract}

\footnotetext{
*Presented at the MT-12 Conference, Lenningrad, U.S.S.R., June 24-28, 1991. TOperated by the Universities Research Association, Inc., for the U.S. Department of Energy under Contract No. DE-AC02-89ER40486.
} 


\title{
Test Results of BNL Built 40-mm Aperture, 17-m-Long SSC Collider Dipole Magnets
}

J. Kuzminski, T. Bush, R. Coombes, A. Devred, J. DiMarco, C. Goodzeit, M. Puglisi, P. Radusewicz, P. Sanger, R. Schermer, J. C. Tompkins, Z. Wolf, Y. Yu\$, and H. Zheng SSC Laboratory, 2550 Beckleymeade Avenue, Dallas, Texas 75237 USA

\author{
T. Ogitsu \\ SSC Laboratory and KEK, National Laboratory for High Energy Physics, 1-1 Oho, Tsukuba-shi, I sraki-ken 305, Japan
}

M. Anerella, J. Cottingham, G. Ganetis, M. Garber, A. Gosh, A. Greene, R. Gupta, J. Herrera, S. Kahn, E. Kelly, G. Morgan, J. Muratore, A. Prodell, M. Rehak, E. P. Rohrer, W. Sampson, R. Shutt, P. Thompson, P. Wanderer, and E. Willen

Brookhaven National Laboratory, Upton, NY 11973 USA

M. Bleadon, R. Hanft, M. Kuchnir, P. Mantsch, P. O. Mazur, D. Orris, T. Peterson, and J. Strait, Fermi National Accelerator Laboratory, Batavia, II 60510 USA

\author{
J. Royet, R. Scanlan, and C. Taylor \\ Lawrence Berkeley Laboratory, Berkeley, CA 94720 USA
}

\begin{abstract}
Eleven $17 \mathrm{~m}$ long, $40 \mathrm{~mm}$ aperture SSC R\&D superconducting collider dipole magnets, bullt at BNL, have been extensively tested at BNL and Fermilab during 1990-91. Quench performance of these magnets and detalls of their mechanlcal behavlor are presented.
\end{abstract}

\section{INTRODUCTION}

Several years ago an extensive R\&D program was launched to develop the prototype for industrially produced superconducting dipole magnets for the SSC. A number of magnets manufactured according to the specifications presented in the SSC Conceptual Design repor [1], achieved the required field strength of $6.6 \mathrm{~T}$ but several magnets experienced poor training and erratic quench behavior. In January 1990, the SSC Machine Advisory Committee recommended enlarging the dipole aperture from $40 \mathrm{~mm}$ to $50 \mathrm{~mm}$ for field quality reasons. Since detailed design, tooling conversion and materials procurements for $50 \mathrm{~mm}$ aperture magnets would take several months, the $40 \mathrm{~mm}$ program was continued in order to provide a base for better understanding of magnet mechanical behavior and its influence on quench performance. During this transition period, eleven 40-mm aperture, 17-m-long SSC dipole magnets were built at Brookhaven National Laboratory [2]. More recently. Fermilab started construction of dipole magnets of similar design, two of which have just completed old test and are the subject of another report to this conference [3]. In this paper we present the quench performance results of the five DD series ( DD0019, 0020, 0026, 0027, 0028) and six DC series (DC0201-206) Brookhaven built

Manuscript received June 24, 1991. This work was supported by the U.S. Department of Energy under Contract No. DE-ACO2. 89ER 40486. superconducting dipole magnets. Magnetic measurements [4] are the subjects of other reports to this conference.

\section{MAGNET DESIGN AND CONSTRUCTION}

\section{A. General features}

All eleven magnets followed the $40 \mathrm{~mm}$ baseline design, with "line-10-line" fit, developed at BNL. The general features are summarized below. The magnetic field is generated by a two layer, $\cos \theta$ type coil. Fig. 1 shows a cross section designated C358D, of the cold mass. The coil is held by stainless steel collars which are spot welded in pairs. The collar stoel is Nitronic $\mathbf{4 0}$ for all magnets excepe DDO019 and 0026 in which Kawasaki high manganese stainless steel was used. The pairs are stacked together to form upper and lower packs which are locked together at the midplane by means of four phosphor-bronze tapered keys. Typically one collar pack per magnet is adapted 10 contain an assembly of 8 beam-type strain gauge transducers to measure azimuthal coil stress, usually located at a minimum of inner coil size [5]. The collared coil assembly is encased in a laminated iron yoke, composed of modules separated by a stainless steel spacer for directing helium flow (see below). Alignment of the yoke, which determines the alignment of the collared coil is provided by two keys at the yoke midplane. A full length, $4.77 \mathrm{~mm}$ thick stainless steel shell, is welded around the yoke laminations forming the cold mass. The coil ends are restrained by G-10 shoes and single piece. $38.1 \mathrm{~mm}$ thick, stainless steel end plates, which are anchored to the stainless steel shell. Each end is preloaded by a set of 4 screws; the screws at the return end are instrumented with "bullet" strain gauge assemblies to measure the force exerted by the coil against the end plate. In all magnets a "cross flow cooling" system, which directs helium flow 


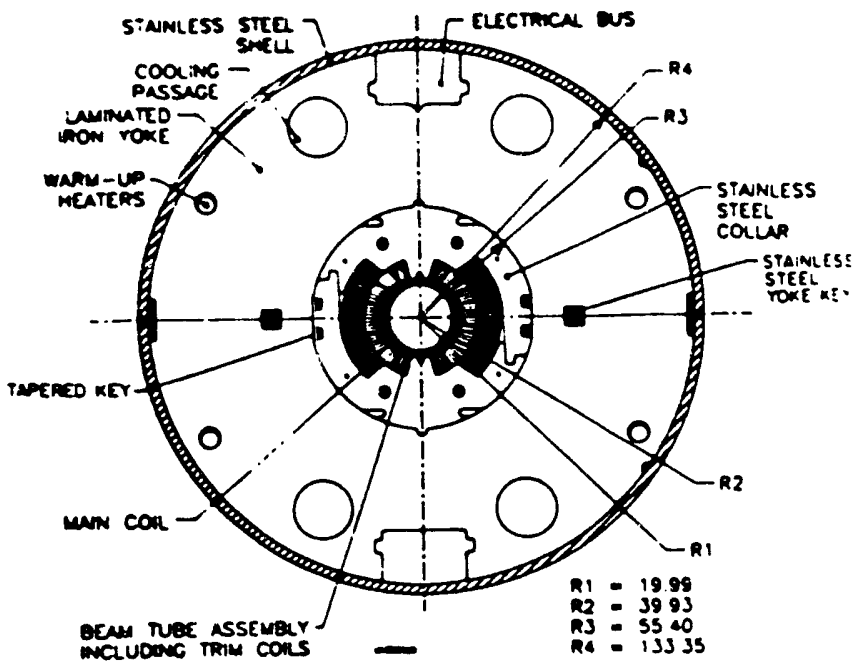

Fig. 1. C358D cold mass cross section. Note that the trim coils were implemented only in DD0020 magnet

perpendicular to the magnet axis, was implemented by using bypass hole flow restrictors and the above mentioned stainless steel lamination spacers [6]. Each magnet has -40 voltage taps for quench diagnostics, all located on the inner layer of the coil, where quenches are most likely to occur.

\section{B. Design Variants}

\section{Superconducting Cables}

The superconducting cable in all tested magnets is made from $\mathrm{Nb}$ (46.5 wt.\%) Ti conductor stabilized with low resistivity copper. The copper-to-superconductor ratio (Cu:SC) of cables for inner coils is nominal 1.5:1 for the magnet of the DD series and for DC0201, 0202, and 0203. For the magnets DC0204-206, the Cu:SC ratio was chosen to be nominal 1.3:1. For the outer coil the Cu:SC ratio was nominal 1.8:1. Filament diameter in both coils is $6 \mu \mathrm{m}$. The $1.6^{\circ}$ keystone angle cable of the inner coils is wound from 23 -strand wire, $0.808 \mathrm{~mm}$ in diameter and the $1.8^{\circ}$ keystone angle cable of the outer coil is wound from 30 . strand wire, $0.648 \mathrm{~mm}$ in diameter. The cable insulation consists of a double layer of $24.5 \mu \mathrm{m}$ kapton, helically wrapped with 55\% overlap, followed by one layer of 0.10 $\mathrm{mm}$ thick fiberglass tape impregnated with epoxy, wrapped with $50.8 \mu \mathrm{m}$ gap between turns.

\section{Collar Shape and Collar-Yoke Interference}

Magnets of the DD series used round collars that are designed to match the inner boundary of the yoke at room temperature. It was found however in the later tests, that the vertical distortion of the coil assembly after collaring assembly was probably excessive and could create gaps between upper and lower yoke halves. Therefore, in the DC series, "anti-ovalized" collars were implemented. In anti- ovalized collars the location of keyways has been modified in such a way that centers of the top and bottom collars are shifted by $254 \mu \mathrm{m}$, resulting in a collar vertical diameler reduction to compensate for the collar distortion. Since reduction of collared coil size could potentially lead to loss of contact to yoke, in the cold state, brass shims of $76.2 \mu \mathrm{m}$ thickness were added at the botiom and top of the collared coil assembly for all magnets of the DC series, after DCO201.

\section{Ramp Splice Region}

In order to provide electrical connections between four quarter coils, a ramp splice is used between inner and outer coil layers. The conductor is ramped up and spliced over a length of $76.2 \mathrm{~mm}$ using $96 \% \mathrm{Sn}-4 \%$ Ag solder. Since the ramp splice is located in the high freld region, it is supported by a specially designed G-10 box. It was found in magnets of the DD series that a number of quenches originated in this area and therefore, in the DC series, inner layer conductor length from the pole turn was epoxied to the adjacent tum.

\section{EXPERIMENTAL PROCEDURE}

The magnets are cold tested at a nominal temperature of $4.35 \mathrm{~K}$. The mass flow of supercritical helium at $4 \mathrm{~atm}$. is typically $40 \mathrm{~g} / \mathrm{s}$ at the Fermilab Magnet Test Facility and $-100 \mathrm{~g} / \mathrm{s}$ at BNL. Magnets cold tested at Fermilab were: DD0019, 0026, 0027, and 0028; the other magnets were tested at BNL. The generic test sequence calls for restricted cool down and generally includes two lest cycles, separated by warm-up to room temperature. Restricted cool down limits the temperature difference between helium inlet and outle of the magnet to $125 \mathrm{~K}$. Initial test cycle starts with conditioning, during which the magnet is cooled to at $3.5 \mathrm{~K}$ and altempts are made to ramp the magnet to $6800 \mathrm{~A}$. One reason behind conditioning is that by lowering temperature, magnet can be operated in regime farther away from the conductor critical surface. Following the conditioning procedure, the magnet is warmed up to $4.35 \mathrm{~K}$ and quench tested. The second test cycle is performed without conditioning. The test quench at $4.35 \mathrm{~K}$ is usually followed by testing at lower temperatures (i. e. $3.85 \mathrm{~K}$ and $3.5 \mathrm{~K}$ ). Cold magnetic measurements are performed during both test cycles, with warm magnetic measurements between the subsequent cycles. Additional test cycles were performed for a number of magnets, e. 8. DD0019,0026, and 0028. In the case of magnets DDOO19, and 0028, "unrestricted cool down" was tried both with and without subsequent conditioning. Testing of magnet DDOO20 was intermpted after the fifth quench because of failure of the quench protection heaters (heater ground fault).

\section{MAGNET TEST RESULTS AND DISCUSSION}

\section{A. Quench performance}

Figure $2 \mathrm{a}$ and $2 \mathrm{~b}$ show two sets of the results of quench performance measurements. Only quenches during 
DDoonn Series Current al Quench

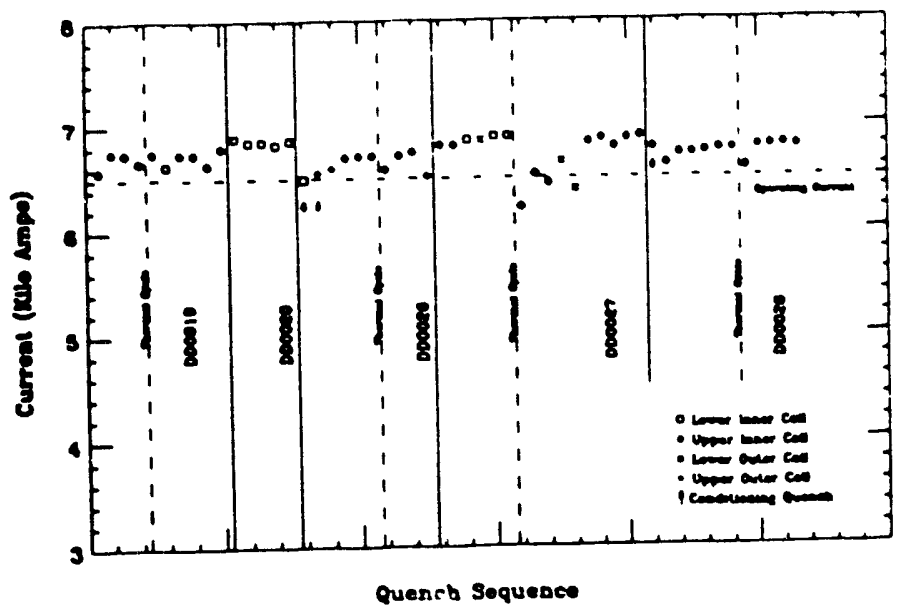

Fig. 2a Quench performance of the magnets of DD series.
TABLE 2

DD AND DC MODEL MAGNETS QUENCH PERFORMANCE DURING 1st TC

\begin{tabular}{|l|c|c|c|c|}
\hline Magnet & $\begin{array}{c}\text { Condition } \\
\text { ing }\end{array}$ & $\begin{array}{c}\text { Nr of } \\
\text { Training } \\
\text { Quenches }\end{array}$ & $\begin{array}{c}\text { First } \\
\text { quench } \\
(\mathrm{A})\end{array}$ & $\begin{array}{c}\text { Plateau } \\
\text { (A) }\end{array}$ \\
\hline DD0019 & OK & 1 & 6581 & 6750 \\
\hline CD0020 & OK & 0 & 6887 & 6853 \\
\hline DD0026 & Q & 3 & 6493 & 6706 \\
\hline DD0027 & OK & 2 & 6817 & 6890 \\
\hline DD0028 & Q & 2 & 6624 & 6750 \\
\hline DC0201 & OK & 0 & 6790 & 6785 \\
\hline DC0202 & $Q$ & 1 & 6804 & 6885 \\
\hline DC0203 & $Q$ & 4 & 6754 & 6800 \\
\hline DC0204 & Q & 7 & 6656 & 6960 \\
\hline DC0205 & $Q$ & 8 & 6554 & 6985 \\
\hline DC0206 & OK & 1 & 6841 & 6920 \\
\hline
\end{tabular}
$\bullet$ Q means that magnet quenched during conditioning Kawasaki high-manganese steiness steel collars

Among the magnets of the DD series, the worst performing magnet was DDO027, which, at the begining of the 2nd TC. exhibited a total of five retraining quenches, three of these were below operating current. These quenches originated in the end sections of the magnet and were later atributed to the lack of the axial preloading, in the cold state. Among the DC magnets the majority of the training quenches originated in the outer coils. This behavior, under current investigation, is thought to be related to subtle changes of collar-yoke interference. The best performing magnets are those with highest axial preloading in cold state e. $8.26 \mathrm{kN}$ in DCO201, $11 \mathrm{kN}$ in DCO202 and $16 \mathrm{kN}$ in the DC0206.

\section{B. Mechanical behavior.}

Azimuthal inner coil stress, averaged over the four layer quadrants, as a function of $\mathrm{I}^{2}$, is shown in Figure $3 \mathrm{a}$ for magnets of the DD series and on Figure 3b. for the $D C$ series. For the DD series, the average stress loss between 0 and $6500 \mathrm{~A}$ is about $20 \mathrm{MPa}$. and there is no indication of inner coil unloading in this range. On the other hand, most of the magnets of the DC series exhibit inner coil unloading at currents of the order of $6500 \mathrm{~A}$. This unloading occurs probably as a result of a combination of lower initial prestress and greater loss of prestress during excitation. A lower level of initial prestress results from a lower level of prestress during assembly, while a greater rate of prestress loss can be related to reduced collar-yoke interference [7]. 


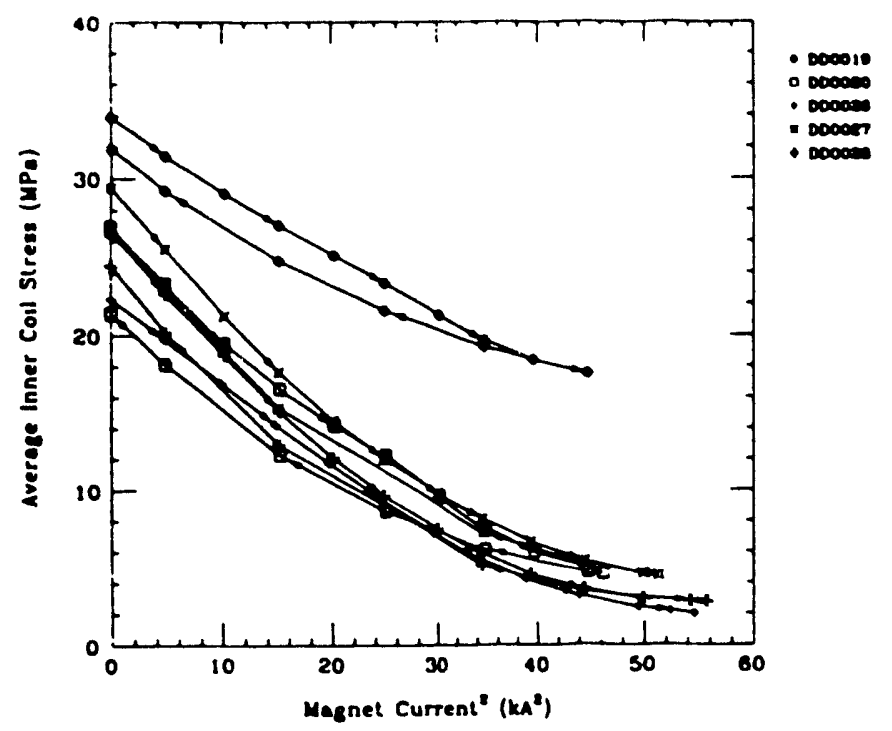

Fig. 3a Azimuthal coil stress as a function of excitation current in magnets of the DD series.

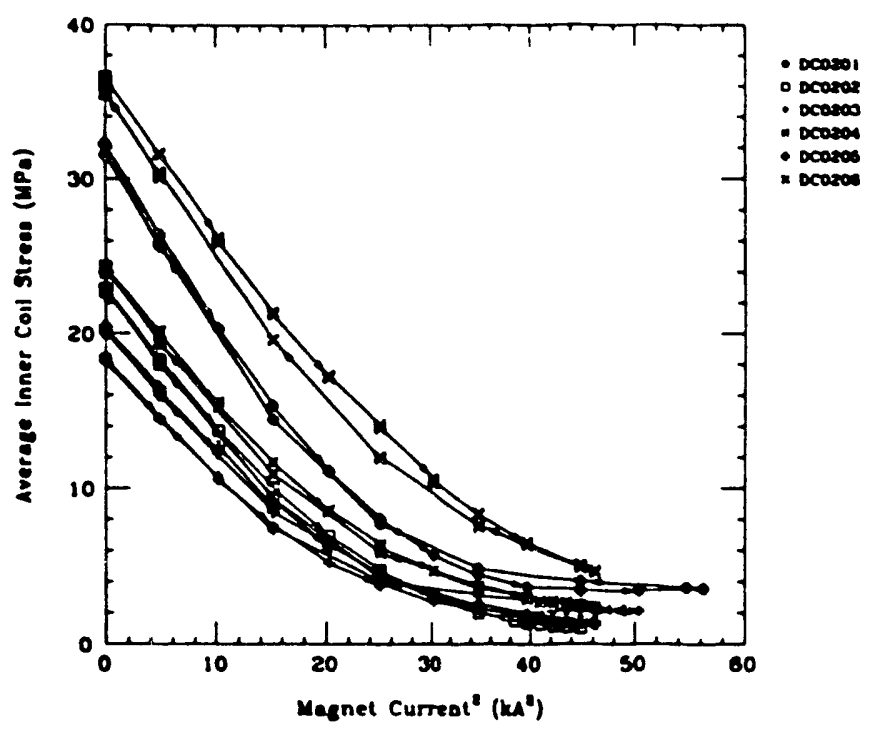

Fig. 3b Azimuthal coil stress as a function of excitation current in magnets of the DC series.

\section{Training and Conditioning.}

There is some evidence with limited statistics, that while conditioning does not eliminate the training: it helps to reduce the number of steps to reach plateau. Although these magnets reached plateau during the first test cycle, they also exhibit retraining at the beginning of the subsequent test cycle. This lack of "memory" would seem to indicate that most of the training is related to thermal effects induced during cool down.

\section{SUMMARY AND CONCLUSIONS}

Eleven full size, $40 \mathrm{~mm}$ aperture SSC R\&D magnets have been built at BNL, following base line design and coll tested to determine their quench performance. Although the quench performance of the most recent magnets shows slightly more quenches than expected, we now have betler understanding of the mechanical behavior of these magnets. The baseline design, embodied in the DD series of magnets, leads to reasonable quench performance. The quench performance of the DC series of magnets, however, seems to indicate a strong sensitivity to subule changes in design parameters - key among them being the collar-yoke interface. Several issues, such as a more realistic cool down scenario. remain to be resolved and will be addressed in the upcoming $50 \mathrm{~mm}$ program.

\section{ACKNOWLEDGEMENTS}

We are grateful to the BNL Staff for their hardwork and dedication during building and cold testing of these magnets. We also wish to thank the staff of the Fermilab Magnet Test Facility for their support of the test program there.

\section{REFERENCES}

8 Permanent address: Institute of Electrical Engineering. Beijing 100080. China

[1] J. D. Jackson, ed., "Conceptual Design of the Superconducting Super Collider", SSC-SR-1020, March 1986; revised 1988.

(2) A.Devred et al., Sutus of $4-\mathrm{cm}$ Aperture, $17-\mathrm{m}$ long SSC dipole Magnet R\&D Program a BNL, Supercollider 3.

[3] J. Strait et al. Tests of Fermilab Built $40 \mathrm{~mm}$ Aperture Full Length SSC Dipole Magnets". paper BA-2 to this conference.

[4] P. Wanderer et al., "Results of Magnetic Field Measurements of $40 \mathrm{~mm}$ Aperture 17-m Long SSC Model Collider Dipole", paper BA-3 to this conference.

(5) C. L. Goodzeit, M. D. Anarella, and G. L. Genetis, "Messurement of Internal Forces in Superconducting Accelerator Magnets with Strain :auge Transducers", IEEE Trans. Mag. 25. No. 2. 1989. pp 1455-1458.

[6] R. P. Schuta and M. L. Rehat. Transferse Cooling in SSC Magnets", Supercollider 1, M. McAshan, ed., 1990. pp. 209-217.

[7] A.Devred et al. Starus of 4-cm Aperture, 17-m long SSC dipole Magnet R\&D Program at BNL - part II, to be published. 


\section{Disclaimer Notice}

This report was prepered as an eccount of work aponeored by an epency of tho Uniced States Government. Neither the Unied States Government of any apency thereot. nor eny of their

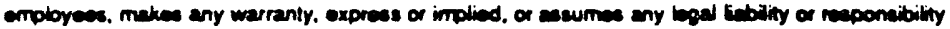
for the eccuracy. completeness, of useluiness of any intormation, epparatus, product, of process

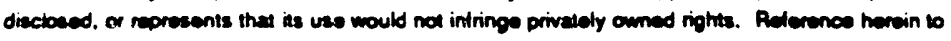
any specific cormmercial product. process. of service by trade name, tredemerk manulecturer, of

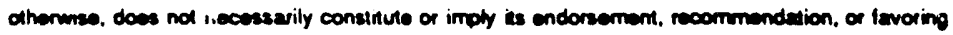
by the United States Government of any apency thereot. The viswe and apinions of authors

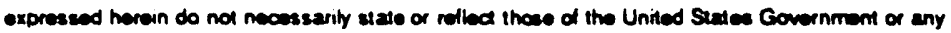
epency thereot.

Superconducting Super Collider Laboratory is an equal opportunity employer. 

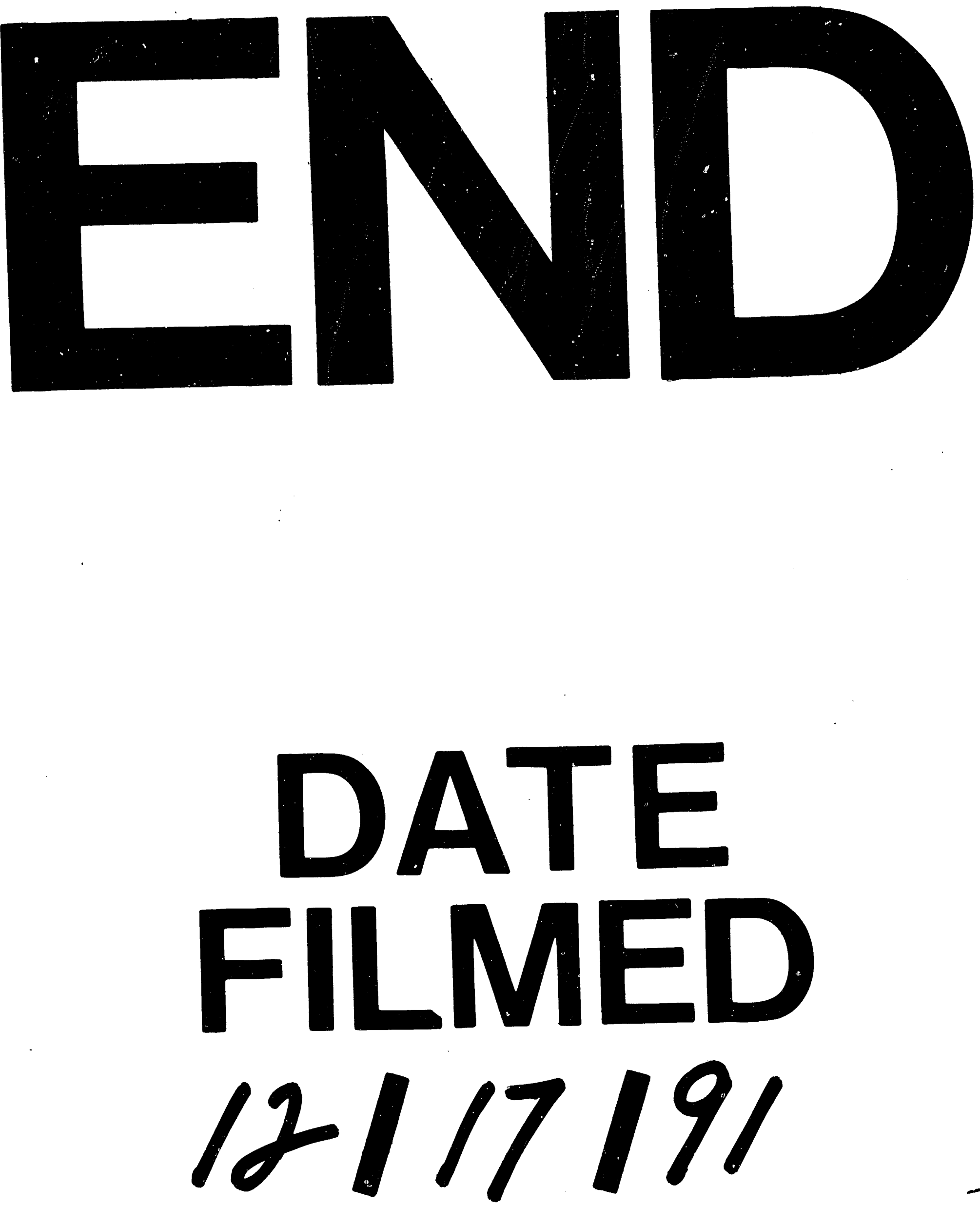
